\title{
LA INTERVENCIÓN E INTROMISIÓN DE LOS CURAS EN LOS PUEBLOS DE INDIOS EN EL PERIODO BORBÓNICO: NAUCALPAN Y TLALNEPANTLA
}

\author{
POR \\ REBECA LÓpez MORA \\ Universidad Nacional Autónoma de México
}

\begin{abstract}
RESUMEN
Los curas párrocos del periodo borbónico en Nueva España fueron instruidos para constituirse en guías espirituales y morales de su feligresía, así como para tener un papel menos protagónico al interior de los pueblos de indios. Pero en este artículo, a través del estudio de dos pueblos, Naucalpan y Tlalnepantla, se demuestra que los curas siguieron interviniendo en muchas formas en asuntos de la convivencia interna de los indios, algunas veces a favor de ellos, y otras en su contra.
\end{abstract}

PALABRAS ClAVE: clero secular, pueblos de indios, Estado de México

\section{THE INTERVENTION AND INTERFERENCE OF THE PRIESTS IN THE PEOPLES OF INDIANS IN THE BOURBON PERIOD: NAUCALPAN AND TLALNEPANTLA}

\begin{abstract}
Priests from the bourbon period in New Spain were instructed, not only to become spiritual and moral guides, but also to have a less leading role in the indigenous towns. Nevertheless, through the study of two towns, Naucalpan and Tlanepantla, it is demonstrated that priests continued intervening in several ways in the indigenous internal connivance issues, sometimes in their favor, and some others against them.
\end{abstract}

KEY WORDS: Secular Clergy, Indigenous Towns, State of Mexico

Recibido/Received 15/03/2011

Aceptado/Accepted 30/04/2011 
La intervención de los párrocos en la vida interior de los pueblos de indios de la Nueva España fue una actividad constante y cotidiana. Relacionarse estrechamente con el cabildo indígena, así como con las distintas facetas de la convivencia de los indios, fue algo que comenzó desde los primeros años de la evangelización. Gran parte de la administración de los pueblos fue un espacio compartido por los indios y los sacerdotes, regulares o seculares. ${ }^{1}$ William Taylor ha afirmado que, hasta mediados del siglo XVIII, un cura enérgico podía actuar como guardián del orden público y la moral, castigar conductas pecaminosas y denunciar delitos graves ante tribunales reales. ${ }^{2}$ Sin embargo, las Reformas Borbónicas trataron de poner cierto límite a las atribuciones de los curas en el campo de la moral pública.

Estos límites los colocaron en un lugar menos protagónico dentro de los pueblos, pues no tendrían un papel esencial en el campo de la cohesión política, aunque siguieron siendo «intérpretes literales» y figuradores de aquel orden imaginado». ${ }^{3}$ Constantemente se pidió a los curas mantenerse «al margen de negocios seculares», guardando sólo su interés en el bienestar espiritual y temporal de los indios. ${ }^{4}$ De hecho, en la última etapa del periodo colonial, se procuró fijar y poner límites a la actuación del cura párroco. ${ }^{5}$

No obstante, la participación de los curas al interior de los pueblos de indios conservó un papel especial, en que muchas veces más que intervención, rozaba en una plena intromisión en la convivencia cotidiana. Con frecuencia la participación de los curas constituyó el «fiel de la balanza» entre los indios y las autoridades o entre los propios indios. Sus opiniones favorecieron a una u otra parte en los diversos enfrentamientos que se vivían al interior de los pueblos de indios, convirtiéndose en un árbitro apreciado dentro y fuera de sus curatos.

El propio William Taylor también reconoce este nuevo papel de los curas como algo menos claro que en tiempos anteriores a los borbónicos. Incluso llegaba a traslaparse con otras autoridades, o a ser contradictorio con su propio ministerio. ${ }^{6}$

\footnotetext{
${ }^{1}$ Rosa CAMELO, «El cura y el alcalde mayor» en Woodrow Borah (Coord.), El gobierno provincial de la Nueva España, $2^{\mathrm{a}}$ ed., México, 2002, 169.

2 W. TAYLOR, Ministros de los sagrado: sacerdotes y feligreses en el México del siglo XVIII, Zamora, 1999, 28.

${ }^{3}$ Ibidem 40

${ }^{4}$ Ibidem 33.

${ }^{5}$ Brian Connaugthon, «El cura párroco al arribo del siglo XIX: el interlocutor interpelado» en A. MAYER (coord.), El Historiador frente a la Historia. Religión y vida cotidiana, México, 2008, 195.

${ }^{6}$ William. TAYLOR, «El camino de los curas y de los Borbones hacia la modernidad» en A. MATUte, Trejo y B. Connaghton (coords.), Estado, Iglesia y sociedad en México, siglo XIX, México, 1995, 100 .
} 
En este artículo se expondrán diversos escenarios de la participación de los curas como el «fiel de la balanza», dentro del espacio parroquial dos pueblos al norponiente del valle de México: San Bartolo Naucalpan y Corpus Christi Tlalnepantla, actuales cabeceras municipales del Estado de México. ${ }^{7}$

Aunque cada una de estas parroquias tuvo sus particularidades, mantienen ciertas semejanzas y cercanía geográfica que vale la pena considerar. Por ello, en primer lugar se darán breves antecedentes de su formación histórica. En segundo lugar, se expondrán diversos ejemplos de esta participación en la última etapa del periodo novohispano. En tercer lugar, se hará referencia al conflicto que sostuvieron los indios de Naucalpan con la Catedral Metropolitana por el uso y posesión de ciertas canteras. Si bien este último caso no involucra al curato local, vale la pena mencionarlo, ya que es un magnífico ejemplo de que la relación de los indios con el clero secular no siempre fue armoniosa.

\section{CONGREGACIONES Y CURATOS: LOS ORÍGENES DE NAUCALPAN Y TLALNEPANTLA}

Los curatos de Naucalpan y Tlalnepantla fueron producto de las congregaciones de indios que realizaron los frailes franciscanos a mediados del siglo XVI. En el caso de Tlalnepantla, la reunión se llevó a cabo alrededor de 1555, a raíz de la cual se unieron las poblaciones de Teocalhueyacan, habitada por otomíes, y la de Tenayuca, habitada por chichimecas nahuatlizados, denominados generalmente como «mexicanos». ${ }^{8}$ Aunque la congregación franciscana pretendió la convivencia de ambos grupos en una sola cabecera, el proyecto fracasó rotundamente. Por ello a partir de 1686 que se establecieron dos gobiernos de indios con sede en Tlalnepantla, uno para cada grupo indígena. No obstante, la administración de los sacramentos continuó atendiendo a ambos grupos en el curato de Tlalnepantla, el cual fue secularizado a finales del siglo XVIII.

Por su parte, Naucalpan probablemente también fue fruto de una congregación de indios, pues el nombre de esta población no se encuentra mencionado en ninguna crónica ni documento pictográfico anterior a 1560. Tanto Naucalpan como Tlalnepantla tenían abundantes recursos naturales para sustentar a los centros poblacionales, entre los cuales cabe mencionar la presencia de río cer-

\footnotetext{
${ }^{7}$ Respecto al nombre de Tlalnepantla, existieron otros pueblos con el mismo nombre. Uno de ellos está cerca de Xochimilco y otro en el actual estado de Morelos. En este artículo se hace referencia a Corpus Christi Tlalnepantla, que perteneció a la alcaldía mayor de Tacuba, que luego sería Subdelegación de Tacuba. Vid. Peter Gerhard, Geografía histórica de la Nueva España, 1521-1810, México, 1986, 254.

${ }^{8}$ En la portada norte de la Iglesia de Corpus Christi Tlalnepantla se puede observar el año de 1557 junto con los glifos de Teocalhueyacan y Tenayuca, por lo que se ha señalado el año de 1555 como probable fecha de la reunión original.
} 
cano, tierra fértil, caminos hacia poblaciones más grandes y estar geográficamente en una zona plana.

A diferencia de la congregación de Tlalnepantla, la iglesia de San Bartolo Naucalpan fue vicaría del curato de San Gabriel Tacuba, hasta que se secularizó, en 1770 y se convirtió en parroquia.

La población de Naucalpan y de Tlalnepantla fue mayoritariamente indígena, compuesta por nahuas y otomíes. Pero esa situación no pudo evitar la llegada de personas ajenas a los indígenas originales, las cuales se fueron introduciendo desde tiempos muy tempranos en las tierras de los pueblos. Ya sea por arrendamientos ilegales, o por matrimonios interraciales, mestizos, mulatos y españoles, convivieron con los indios cotidianamente.

Otro aspecto que vale la pena resaltar es el hecho de que ambas poblaciones estaban muy cerca de la capital virreinal, en lugares de los cuales partían caminos importantes. Tlalnepantla se encontraba prácticamente al pie de la ruta hacia Zacatecas. También por ahí se tomaba una ruta que atravesaba la zona montuosa de los actuales municipios de Atizapán y Nicolás Romero, que se dirigía hacia el Bajío a través de Chapa de Mota e Ixtlahuaca.

Naucalpan, por su parte, estaba al inicio de uno de los caminos que se dirigía hacia el valle de Toluca, atravesando la cadena conocida como el Monte de las Cruces. Cabe mencionar que, más que el de Toluca, el camino más transitado de esta zona era el que unía la ciudad de México con el Santuario de los Remedios, localizado a dos kilómetros de San Bartolo Naucalpan. Esta imagen mariana fue muy reverenciada durante la época colonial, y con frecuencia era conducida a la capital en casos de desastres naturales o epidemiológicos.

Ambos curatos permanecieron bajo la tutela de los frailes franciscanos hasta mediados del siglo XVIII. A partir de 1753, y como consecuencia de las Reformas Borbónicas, llevada a cabo en todo el Imperio Español, los curatos que tradicionalmente habían permanecido en manos de órdenes religiosas, pasaron a la tutela del clero secular. La rapidez con la que se llevó a cabo este proceso no fue igual, pues en muchos casos la llegada de los clérigos dependía de la renuncia o muerte de los frailes. ${ }^{9}$

La secularización de Tlalnepantla se realizó en $1754,{ }^{10}$ apenas un año después de la primera cédula real al respecto. Por su parte, Naucalpan fue elevado

\footnotetext{
${ }^{9} \mathrm{~W}$. TAYLOR, Ministros de lo sagrado... 121.

${ }^{10} \mathrm{H}$. VERA, Itinerario parroquial del Arzobispado de México y reseña histórica, geográfica y estadística de las parroquias del mismo arzobispado, Amecameca, 1880, 72. Su primer párroco fue el Lic. Don Antonio Padilla y Rivadeneira.

Hispania Sacra, LXIII

128, julio-diciembre 2011, 545-567, ISSN: 0018-215-X
} 
al nivel de parroquia el 18 de diciembre de 1769. La toma de posesión de su primer párroco fue el 15 de junio de $1770 .{ }^{11}$

Aunque en algunos lugares se ha documentado la oposición de la población india ante la remoción de los religiosos, ${ }^{12}$ tal parece que en estos dos curatos no hubo ningún movimiento de rechazo a la medida de sustitución. Los clérigos muy pronto se ajustaron a la vida interna de los pueblos, de tal manera que comenzaron a ejercer las funciones de arbitraje que siempre habían tenido los frailes franciscanos. Además, sostuvieron diversos niveles de relación con los indios, que no siempre fueron armoniosas.

Vale la pena resaltar que, a pesar de que ambos fueron curatos rurales, no eran del mismo nivel. El de Tlalnepantla estaba considerado como de primer nivel, o sea de los más deseados. ${ }^{13}$ Esto se debía las posibilidades económicas y número de sus habitantes. En cambio, el de Naucalpan estaba catalogado como de tercer nivel. No obstante, en ambos casos los curas párrocos que llegaron a raíz de la secularización formaron parte del grupo de clérigos interesados en la carrera eclesiástica. Concursar por estos curatos rurales fue sólo un paso para su ascenso, por lo que había una gran movilidad en estos curatos. ${ }^{14}$ Las parroquias cercanas a la ciudad de México estaban especialmente disputadas, pues de esa manera los curas podían seguir enterados de los movimientos que se daban alrededor del cabildo catedralicio, y así, cuidar sus intereses personales.

El primer clérigo de Tlalnepantla fue el Licenciado don Antonio Padilla y Rivadeneira. Dentro de su curriculum estaba haber sido Colegial Mayor en el Colegio de Santa María de Todos los Santos, abogado de la Real Audiencia de México y comisario del Santo Oficio. ${ }^{15}$

Por lo menos hasta antes de 1755 don Antonio Padilla ejercía activamente la abogacía; esto se puede inferir por un documento que data de esa fecha, apenas un año después de haber recibido el curato de Tlalnepantla, en el que don Antonio Padilla otorga poder escrito a otro abogado, para responder a un litigio que tenía en el Provisorato de Indios y Chinos del Arzobispado de la ciudad de México, ya que su nueva situación como párroco le impedía atender dichos negocios. ${ }^{16}$

11 A. SÁNCHEZ, Cronología de Naucalpan a través de sus documentos parroquiales, (versión no publicada facilitada por el autor en primer manuscrito).

${ }^{12}$ Algunas parroquias que tuvieron movimientos de oposición contra la secularización se encontraban en Xilotepec, Cuernavaca, Chalco, Cuautla. W. TAYLOR, Ministros de lo sagrado...30.

13 W. TAYLOR, Ministros de lo sagrado...163.

14 Ibidem 162.

15 Ibidem 72.

16 Archivo General de la Nación México (en adelante AGNM), Indiferente Virreinal, Caja 1687, exp. 41, (Civil), f. 1 . 
El cargo de comisario del Santo Oficio lo solicitó directamente al Tribunal en 1768, con el argumento de que no había quién ejerciera este cargo en Tlalnepantla, así como en otros partidos circunvecinos. Además, don Antonio recibió varias comisiones semejantes en el pasado, razón por la cual deseaba «dedicarse a su ejercicio con mayor atención y esmero». Con ese nombramiento recibiría grandes honores, así como el goce de diversas gracias e indulgencias. ${ }^{17}$

Llama la atención que, habiendo ocupado tan importantes cargos en la capital virreinal, hubiera tenido interés en concursar por el curato de Corpus Christi, el mismo que obtuvo sin ningún problema; pero, como se mencionó antes, Tlalnepantla era un curato de primera categoría. En 1746 Villaseñor y Sánchez calificó a esta cabecera como un pueblo grande, que contaba son ochocientas cincuenta y dos familias de indios, así como un gran cantidad de gente blanca. Hacia 1792 su población era de aproximadamente de 3,500 personas, entre indios y no indios, ${ }^{18}$ incluso tenía más personas que las que habitaban Tacuba, sede de la subdelegación tras la implementación de la Ordenanza de Intendentes. Todo ello hace pensar que las ganancias obtenidas por derechos y obvenciones fueran atractivas para el párroco, a pesar del la limitación que se les puso a través de la regulación de las cuotas por servicios. ${ }^{19}$

En el caso de Naucalpan los primeros párrocos permanecieron muy poco tiempo. Su primer párroco fue don Joseph Mariano Sánchez Montero, quien murió apenas tres años después de haber ocupado este curato. De forma interina, fue nombrado el doctor Joseph Mariano Ramírez Echevarri, que por su grado académico así como por las relaciones que tenía con el cabildo catedralicio, demostraba ser una persona con una carrera en ascenso. En 1774 fue nombrado el siguiente párroco, el doctor don Ramón Pérez, quien va a realizar un informe detallado de la situación ruinosa en que se encontraban tanto la iglesia parroquial como las capillas de visita, denominado Statu animorum.

En estos tres casos nos podemos percatar de que Naucalpan, no obstante que era un curato rural de poca monta, fue atractivo para clérigos con una alta preparación académica, probablemente interesados en obtener más recursos económicos. Estos dos elementos -preparación e interés económico- motivaron a los curas a realizar una insistente revisión del manejo de los bienes de cofradías, como veremos más adelante.

Si bien las Reformas Borbónicas procuraron que los sacerdotes se abocaran preferentemente al cuidado espiritual de los indios, poniendo énfasis en su papel

\footnotetext{
${ }^{17}$ AGNM, Inquisición, vol. 847, exp. 1076, f.1.

${ }^{18}$ Son datos aproximados, haciendo una multiplicación de 5 individuos por cada tributario o familia de vecinos. Los datos de los no indios provienen del padrón de 1792, AGNM, Padrones, vol. 6, fs. 204-208v. Los de indios fueron extraídos del Reglamento de 1805, AGNM, Indios, vol. 79, exp. 5.

19 W. TAYLOR, «El camino de los curas y de los Borbones... 94.
} 
de maestro, es un hecho que los curas continuaron interviniendo en ciertos momentos, y casi de forma silenciosa, en el devenir de los pueblos, como se demostrará en los ejemplos provenientes de los curatos ya mencionados. Para hacer el análisis de la participación de los curas en la vida de los pueblos, los casos se han agrupado de la siguiente manera: Los curas como testigos de calidad; como administradores de los bienes de la parroquia; los curas y su relación con los bienes de cofradías; como rentistas de los indios; y el caso especial de los prebendados de la Arquidiócesis de México contra los indios de Naucalpan, por el uso de las canteras de Los Remedios. Por último, se hace una referencia a su testimonio de calidad durante los aciagos tiempos de la guerra de Independencia.

\section{LOS CURAS COMO TESTIGOS DE CALIDAD}

Los pueblos de indios fueron el escenario de continuas disputas. La posesión del agua y la tierra, las elecciones de oficiales de República y la presencia de «intrusos»-forma despectiva con la que eran señalada la gente ajena al pueblo- fueron algunos de los diversos motivos que redundaron en enfrentamientos durante la época colonial. En muchos litigios fue necesario recurrir a testigos «de calidad», que dieran una opinión confiable a los jueces, ya sea ante el Juzgado General de Indios, o ante el Alcalde Mayor o el Subdelegado de Intendencia. Estos testigos fueron los curas, tanto antes como después del proceso de secularización de las parroquias. Su testimonio fue determinante para la resolución de los conflictos.

Para ilustrar cómo los curas daban importantes testimonios en caso de enfrentamientos al interior de los pueblos, tenemos dos ejemplos provenientes del periodo previo a la secularización. El primero data de 1714, en medio de un enfrentamiento que surgió a raíz de las elecciones de República, entre los indios otomíes de Tlalnepantla. Aunque el proceso había dado el triunfo a don Balthasar Martínez, el resultado fue puesto en duda por don Domingo Ignacio de los Santos, con el argumento de que el primero era un mal ejemplo para el pueblo. En su declaración afirmaba que era común verlo borracho, ya que tenía una pulquería en su casa particular. Para dirimir la verdad, se hizo necesaria la intervención del padre guardián del convento, quien conocía a la perfección a ambas personas, pues don Domingo Ignacio había sido durante varios años fiscal de la Iglesia.

En su testimonio, el fraile franciscano, a quien se le reconocía por ser guardián y ministro de indios, no habló mal de ninguno de los dos contendien tes, aunque reconocía la vieja rivalidad que había entre ambos. El testimonio del fraile dio elementos al Alcalde Mayor para ratificar a don Balthasar en el gobierno, pues no se comprobaron las malas conductas que se le imputa- 
ban. ${ }^{20}$ Es evidente que el fraile conocía a sus feligreses de una forma cercana, por lo que su opinión fue determinante para la resolución del conflicto.

Los enfrentamientos por el poder no cesaron entre los otomíes de Tlalnepantla, por lo que en 1746 de nuevo se tomó el testimonio del cura párroco para que las autoridades juzgaran al respecto. En este caso, fueron los propios naturales quienes pidieron a Fray Antonio Martínez de Moctezuma, que interviniera a su favor para acabar con los abusos de autoridad cometidos por su gobernador, el ya mencionado don Domingo Ignacio de los Santos. Este personaje se había rodeado de una camarilla que lo elegía cada dos años, por lo que ocupó intermitentemente el cargo desde 1716.

En una extendida carta dirigida al Alcalde Mayor de Tacuba, el párroco dio su opinión sobre diversos aspectos de la vida interior del pueblo, como eran las elecciones de República. Éstas eran calificadas negativamente por estar plagadas de vicios, ya que obtenía provecho de la inocencia de los viejos del pueblo, a los que tachaba de ignorantes, pues «ni entienden ni saben lo que han de practicar».

Otros abusos del gobernador eran el desfalco de la caja de comunidad, así como la amistad «escandalosa»-léase adulterio- que públicamente llevaba con una india del pueblo de Atizapán. Por si esto fuera poco, el saqueo de los bienes de los indios había impedido que éstos pudieran adquirir las ceras para la fiesta del jueves santo, lo que había provocado una vergüenza pública ante sus vecinos, los indios mexicanos de Tenayuca, que también asistían a la iglesia de Corpus Christi. ${ }^{21} \mathrm{Al}$ final de su larga exposición de motivos, fray Joseph Antonio pidió justicia a través del recordatorio de la obligación que tenía el Rey de cuidar a sus vasallos.

Gracias a las quejas del párroco, las autoridades dieron curso a una profunda investigación al respecto: enviaron una comisión que revisó la caja de comunidad, las cuentas del pueblo y recavó información testimonial suficiente, por lo cual don Domingo Ignacio fue destituido para posteriormente ser encarcelado durante varios años.

En este caso, el testimonio del cura fue determinante para que las quejas de los indios fueran escuchadas. De otra manera nunca se hubiera hecho justicia. Llama la atención que los abusos de este gobernador se extendieron durante muchos años, y no fue sino hasta que los otomíes carecieron de recursos suficientes para cubrir los gastos de las fiestas de Semana Santa, que el cura decidió tomar cartas en el asunto. ${ }^{22}$

${ }^{20}$ AGNM, Indios, vol. 39 , exp. 35, fs. 52-58 v

${ }^{21}$ AGNM, Criminal, vol. 649, exp. 13, fs. 157-170.

22 Este caso es tratado en forma extensa en Rebeca LóPEz MoRA, «La aristocracia del pueblo. Cacique advenedizos en Tlalnepantla, siglo XVIII», en Nuevo Mundo Mundos Nuevos, (en línea) Debates, 2011, http://nuevomundo.revues.org/60656

Hispania Sacra, LXIII

128, julio-diciembre 2011, 545-567, ISSN: 0018-215-X 
Después de la secularización de las parroquias, el testimonio del cura siguió siendo una herramienta de gran importancia para dar solución a problemas locales. En 1776, el gobernador de mexicanos de Tlalnepantla, a nombre de su pueblo, interpuso una demanda para desalojar del barrio de los Reyes, a don José de Robles, comerciante español, y a su esposa, doña Petra Leonor Martínez, esta última india natural de dicho pueblo. Se les acusaba de haber tomado, de forma ilegítima, ciertas tierras que contenían varios árboles y magueyes del pueblo.

Doña Petra era viuda de don Carlos del Castrillo, quien había sido gobernador de mexicanos muchos años antes, por lo contaba con una privilegiada posición dentro del barrio. Al contraer segundas nupcias con un español, la presencia del matrimonio comenzó a causar molestias a los indios; éstos alegaban que los acusados inquietaban al pueblo, argumento, por cierto, muy común en conflictos con intrusos de los pueblos.

En el fondo, los indios querían que los acusados devolvieran ciertas tierras que doña Petra tenía en su poder, y que según ella, formaban parte de la herencia que había recibido de su primer marido. El virrey dio sentencia a favor del gobernador de indios, ante lo cual don José Robles y su esposa, doña Petra, se inconformaron. Por ello, el abogado del matrimonio acusado pidió la intervención del cura de Tlalnepantla, el ya mencionado Licenciado don Antonio de Padilla y Rivadeneira, como testigo de calidad.

En 1781, el cura envió una carta en donde afirmaba conocer perfectamente a estas personas, desde su llegada a la parroquia. Afirmaba que don José era una persona tranquila, dueño de una cacahuatería; y que, por su parte, doña Petra tenía las virtudes de una buena cristiana, tales como recibir de continuo los sacramentos, vivir metida en su casa y poseer buenos modales, todo lo cual les habían atraído estimaciones innumerables de los naturales del barrio. Sin embargo, su testimonio no resolvió la posesión de la tierra en conflicto, ya que el cura se dijo ignorante respecto a quién era el dueño de los predios. Y para hacer más confusa su argumentación, terminaba diciendo lo siguiente: creo firmemente que ni doña Petra es dueña de todas la tierras que litiga...ni tampoco los indios, sino que todos tienen parte considerable..$^{23}$

Este caso pone de manifiesto que el cura conocía a gran parte de su feligresía, pero probablemente decidió no favorecer a ninguna de las dos partes, para evitar un enfrentamiento con los indios del pueblo. El haberlo hecho así le hubiera atraído la animadversión del gobernador, lo cual hubiera entorpecido su labor apostólica.

\footnotetext{
${ }^{23}$ AGNM, Tierras, vol. 2621, exp. 17, fs. 1-23.
} 
Los testimonios vertidos por los curas no siempre fueron en litigios o conflictos entre los miembros de la feligresía. Algunas veces la calidad de su opinión fue aprovechada por las autoridades virreinales para resolver asuntos diversos. Este fue el caso de la petición que en 1811 hiciera don Guillermo Guauxochitl, gobernador de la parcialidad de mexicanos de Tlalnepantla, para vender cierta tierra. Cabe recordar que para esa fecha, los Reglamentos de los bienes de los indios ya se había implementado en casi todos los pueblos, lo que implicó un control estricto en los montos de gastos y entradas, dejando la diferencia de ambos como el sobrante de la comunidad, a cargo de la Contaduría de Propios y Arbitrios.

Uno de los gastos reglamentados fue el de las fiestas religiosas, ya que se pensaba que había mucho dispendio en ellas por parte de los indios. Las «ventajas» del Reglamento fueron comunicadas por empleados reales a los pueblos a partir de 1786, en una junta a la que concurrieron los oficiales de república, los ancianos y el cura párroco. ${ }^{24}$ Este detalle es importante, ya que se buscaba la aceptación de los criterios virreinales por parte de cada uno de los participantes, incluido el cura, quien debía someterse al monto de gastos religiosos asignado por cada reglamento.

Uno de las principales consecuencias de dicho Reglamento consistió en la retención, por parte de la Contaduría, de los ingresos sobrantes de los bienes de comunidad; los indios tenían acceso a ellos, a menos que comprobaran tener una imperiosa necesidad. ${ }^{25}$ En vista de que no podían aprovechar sus bienes de comunidad, tal como lo hacían en el pasado, muchos pueblos recurrieron al reparto de tierras entre sus miembros, a la ocultación de éstas, o como en el caso de Tlalnepantla, a su venta.

En 1811 el gobernador de los mexicanos exponía ante el subdelegado de Tacuba que los gastos de la fiesta de Corpus Christi, celebración principal de dicho curato, no podían ser sufragados con el monto que se había determinado en el Reglamento de su pueblo. Por ello pedía permiso para enajenar un terreno que formaba parte del denominado Potrero de los Reyes, tierra que usualmente se rentaba para aportar dinero a la caja de comunidad. Dicho terreno había sido repartido, casi en su totalidad, entre los miembros del pueblo, pero todavía restaba una porción que podía adquirir una india de dicho lugar, por la cantidad de 300 pesos. Para saber lo que procedía al respecto, el subdelegado pidió la opinión del cura párroco, quien a pesar de aceptar que la cantidad contemplada en el Reglamento para los gastos de la fiesta patronal era suficientes, en ese año se

\footnotetext{
${ }^{24}$ AGNM, Indios, vol. 79, exp. 5, f. 93 v.

25 Respecto al sobrante de los reglamentos de indios y sus montos, ver a D. TANCK DE ESTRADA, Pueblos de indios y educación en el México Colonial, 1750-1821, México, 1999, 77-152.
} 
había gastado más de lo normal, hasta llegar a 50 pesos, cantidad que debió aportar el propio cura.

En vista de que todavía el gobernador de indios le debía el dinero prestado, el cura no dudó en afirmar que, la única forma que él veía para obtener los recursos mencionados, era poner en venta la referida tierra, y que el resto de ese dinero sería incluido como sobrantes de comunidad. Este testimonio fue muy importante, ya que el subdelegado de Tacuba, tomando en cuenta lo dicho por el cura, recomendó aceptar la propuesta de gobernador, a fin de proceder a dicha venta. ${ }^{26}$

En este último caso, el testimonio del cura favoreció a los indios, a pesar de que quien promovió su participación fue una autoridad superior, como lo era el subdelegado de Tacuba.

Aunque William Taylor menciona que probablemente después de la secularización de las parroquias, las opiniones y argumentaciones presentadas por los curas ante la corte fueron teniendo menos peso, ${ }^{27}$ los casos presentados nos indican que tuvieron un papel igual de relevante que antes de las reformas, y que su papel de testigos de calidad fue determinante en conflictos escenificados al interior de los pueblos, o con autoridades virreinales. Algunas veces sus afirmaciones debieron contar con cierto grado de ambigüedad, a fin de no allegarse el enojo de una de las partes del conflicto. En otros, fueron la base para que la autoridad emitiera su resolución

\section{LOS CURAS COMO ADMINISTRADORES DE LOS BIENES DE LA PARROQUIA}

Como se ha mencionado, algunas de las atribuciones de los párrocos fueron acotadas con las Reformas Borbónicas; en especial se hizo énfasis en que los clérigos no se mezclasen en asuntos que no fueran estrictamente relacionadas con el bienestar espiritual de su feligresía. Sin embargo, en ciertos aspectos relacionados a las finanzas de pueblo, en especial sobre los bienes de la Iglesia y de algunos grupos eclesiásticos, los curas fueron instruidos para ejercer su supervisión. ${ }^{28}$

En ese sentido, el primer párroco de Tlalnepantla, el muy mencionado don Antonio Padilla de Rivadeneira, había celebrado en 1764, un contrato de arrendamiento por un término de dos años, con don Antonio González, de unas tierras localizadas en San Francisco Atizapán, y que eran identificadas como

\footnotetext{
${ }^{26}$ AGNM, Tierras, vol. 2506. exp. 1

27 William TAYLOR, «El camino de los curas...op. cit. 97.

28 W. TAYlor, Ministros de lo sagrado...op. cit. 32 .
} 
tierras del Santo tutelar de aquel pueblo. A cambio, González, quien era vecino de Atizapán -que en ese tiempo era visita de Tlalnepantla- se comprometió a pagar la construcción de la Iglesia de dicho lugar, para lo cual debía entregar doscientos pesos anuales. El costo total de la construcción había sido valuada en 2,500 pesos..$^{29}$

El nombramiento que sustentó el cura párroco para llevar a cabo dicho contrato fue de Ecónomo de los bienes de su parroquia, y por lo tanto era representante legal de los naturales de ese lugar. ${ }^{30}$ Se hicieron otras escrituras posteriores, una de 1765, y otra más, cuatro años después, con lo que aumentaba la cantidad de tierra en arrendamiento. La mayor parte estaba cultivada con magueyes, actividad muy rentable en esos años por la elaboración del pulque.

Hacia 1766, término de la primera escritura, se llevó a cabo la mayor parte de la construcción de la iglesia. Sin embargo, González dejó de pagar lo acordado, por lo que en 1778 comenzó un largo litigio, en el cual se nombró como juez fiscal al bachiller don Manuel Carrera, cura y juez eclesiástico del pueblo de Tacuba, quien en compañía de un maestro de arquitectura y agrimensor, y del propio cura de Tlalnepantla, hizo una visita a la iglesia de Atizapán.

Si bien gran parte del templo estaba construido, faltaba rectificar el área que daba al sur, así como realizar la sacristía, el coro, una vivienda para el párroco y la reparación de la bóveda. Dichas obras no se llevaron a cabo, por lo que, ocho años después, en 1786, se le exigió a González el pago de 400 pesos. Para ese momento, la iglesia se encontraba en pésimas condiciones, pues estaba casi derruida.

Finalmente, el litigio no se resolvió, pues a pesar de haber recurrido a varios fiadores, González no cubrió el monto de su deuda. Su única defensa fue culpar a un muerto, pues afirmó haber pagado el total de su deuda a don Antonio Padilla, quien había fallecido en 1791 sin decir palabra respecto al finiquito del acusado. Antonio González murió un año después, quedando pendiente el pago de su deuda, e inconclusa la construcción de la iglesia de Atizapán. ${ }^{31}$

En este caso, a pesar de que la parte acusada puso en duda la integridad moral del cura párroco, la defensa de González nunca pudo probar tal afirmación, y en cambio, sí se puede corroborar el interés que don Antonio había puesto en dicha construcción, ya que él era representante del común del pueblo. Las tierras no eran propiamente de la Iglesia, sino que pertenecían a los bienes comunales, pero estaban destinados al culto del santo patrono. En este caso, los esfuerzos del cura por defender los intereses de la iglesia y del pueblo, fueron en vano.

\footnotetext{
${ }^{29}$ AGNM, Tierras, vol. 10, $2^{\mathrm{a}}$ parte, cuad. $4^{\mathrm{o}}$, f. $113 \mathrm{v}$.

${ }^{30}$ AGNM, Tierras, $1^{\text {a }}$ parte, exp. 3, f. 120.

${ }^{31}$ AGNM, Tierras, vol. $10,2^{\mathrm{a}}$ parte, cuad. $4^{\mathrm{o}}, \mathrm{f} .113 \mathrm{v}$.
} 
El segundo ejemplo de este rubro se desarrolló en el pueblo de Tlalnepantla, en la parcialidad de mexicanos. En 1818, el maestro de primeras letras solicitó le fuera vendido un pequeño terreno dentro del fundo legal del pueblo. Ante esa petición se presentó la inconformidad del indio Victoriano García, quien afirmaba haber poseído dicho terreno desde hacía doce años. Dado que se trataba de tierras destinadas al culto de Santa María Magdalena, el Subdelegado de Tacuba solicitó la opinión del cura para otorgar una resolución justa. El párroco envió una certificación en donde daba su apoyo al Maestro de Primeras Letras, quien, en su opinión, traía mucho beneficio a los fieles de su comunidad, pues incluso también era maestro de música.$^{32}$ La posición del párroco fue requerida dado que se trataba de una tierra que formaba parte de una antigua obra pía, a pesar de estar dentro del fundo legal de los mexicanos de Tlalnepantla.

Al final, y por el testimonio del gobernador de indios y del teniente de ese lugar, se decidió amparar al indio que poseía dicha tierra, por haber demostrado que las ocupaba desde hacía mucho tiempo, así como por haber cumplido el pago anual destinado a las misas de Santa María Magdalena. En este caso, el cura estuvo en contra de la opinión de su propia feligresía, tratando de favorecer a la gente de razón.

No cabe duda que estos ejemplos delatan que los curas solían tener puntos de vista diferentes ante cuestiones que enfrentaban a los indios con los no indios. Si bien en algunas ocasiones tuvieron opiniones ambiguas, para no enfrentarse abiertamente al común del pueblo, en otras no dudaron en favorecer a vecinos españoles, que tuvieron actitudes que molestaban a los indios. Llama la atención que en ninguno de los dos pueblos que hemos tomado como referencia, se dieron conflictos que derivaran en conductas violentas frente a llamados «intrusos» o más aún, frente la actitud del cura párroco.

\section{LOS CURAS Y LOS BIENES DE COFRADÍAS}

El asunto de los bienes de las cofradías rurales dio lugar a muchos conflictos entre feligreses y clero secular durante el siglo XVIII. Desde los siglos anteriores se había permitido que los indios fundaran este tipo de hermandades para financiar las fiestas patronales, pero en la mayoría de los casos carecían de constituciones aprobadas por el obispo. No obstante, habían sido toleradas por obispos y clérigos porque ayudaban a mantener al sacerdote, las fiestas y las prácticas religiosas. ${ }^{33}$

${ }^{32}$ AGNM, Tierras, vol. 2621, exp. 6, f. 21.

${ }^{33}$ D. TANCK, «Los bienes y la organización de las cofradías en los pueblos de indios del México Colonial. Debate entre el Estado y la Iglesia», La iglesia y sus Bienes. De la amortización a la nacionalización, México, 2004, 37. 
Con la secularización, se comenzó a poner énfasis en que los curas debían controlar el capital de las obras pías, así como una mayor participación de los curas en la elección de los mayordomos. Había una convicción generalizada entre el clero secular de que los bienes de las cofradías estaban manejados de forma irregular, y que con frecuencia personas particulares vendían o alquilaban las tierras y animales de las obras pías en beneficio individual. ${ }^{34}$

En la década de 1770 se ordenó la extinción de cofradías que no tuvieran constituciones, tanto en España como en América, por lo que se dio paso a una revisión de estas hermandades en todos los curatos. ${ }^{35}$

En Naucalpan existían varias de estas cofradías irregulares. Las más grandes estaban radicadas en la iglesia parroquial de San Bartolomé, y eran las del Santísimo, la de las Ánimas y la del patrón de la cabecera, San Bartolomé. Además había otras menores situadas en las capillas de visita, las cuales contaban con mínimas extensiones de tierra. Su producto financiaba los gastos de las fiestas locales, como pólvora, ruedas de cohetes, cera y flores. ${ }^{36}$

El primer párroco de Naucalpan, don Joseph Sánchez Montero, en atención al interés del Obispo por revisar las cuentas de las cofradías, determinó que había muchas irregularidades en los libros de cada una, por lo que nombró a don Joseph Montes de Oca, español vecino del pueblo, en el cargo de mayordomo de la cofradía del Santísimo Sacramento. Esto suscitó que los indios enviaran un escrito de inconformidad por la indebida actuación de su párroco.

Don Joseph Sánchez murió poco después del escrito de los indios, por lo que éstos aprovecharon la coyuntura para hacer a un lado a Montes de Oca como mayordomo.

Como sucedía frecuentemente cuando los no indios ya no eran bien vistos en los pueblos, el gobernador y demás oficiales acusaron a Montes de Oca de ser extravagante, así como de inquietar y perjudicar a los indios.

El cura interino, el doctor don Joseph Mariano Ramírez Echevarri, fue comisionado para dirimir este problema, como una especie de testigo de calidad, y en el papel de defensor de los bienes de la cofradía. Sin embargo, su testimonio no fue del agrado de los indios, pues además de verificar que la cofradía no contaba con constituciones que especificaran que el cargo de mayordomo de ésta debía recaer en un indio, el cura párroco encontró un escrito de su predecesor, en que daba un testimonio nada ventajoso para los demandantes. Afirmaba que las cofradías de ese curato las había hallado enteramente perdidas, y no por

\footnotetext{
${ }^{34} \mathrm{~W}$. TAYLOR, Ministros de lo sagrado... 461.

${ }^{35}$ D. TANCK, «Los bienes...» 46-47

${ }^{36}$ Archivo Parroquial de San Bartolo Naucalpan (en adelante APSBN), Serie Sacramental, Caja 53, Statu animarum, f. 2. 
falta de bienes, las más de ellas, sino por una disipación, y latrocinio que a cara descubierta han hecho y hacen los mayordomos, como en algún modo se puede percibir por los libros.

En su calidad de interventor de dichos bienes, no había aprobado sus cuentas, e incluso había puesto al tanto del asunto al Juez Provisor de la Catedral. Por ello decía haber tomado el control de los bienes de la cofradía, e incluso aceptaba haber sembrado, por su cuenta, una tierra de la dicha corporación, y haberle permitido a don Joseph Montes de Oca, otro pedazo de tierra. El cura afirmaba que, con el fruto de ambos terrenos, se podría sufragar el adorno del altar. Algo semejante había hecho con las cofradías de San Bartolomé y de las Ánimas, de lo cual informaría al Provisor en cuanto tuviera claras las medidas que tomaría en adelante.

Cabe mencionar que las autoridades eclesiásticas y del Estado estuvieron convencidas en todo tiempo, que los indios gastaban excesivamente en sus fiestas patronales, y que esos bienes podrían tener un mejor destino que los vicios y las borracherías que se presentaban en cada fiesta patronal.

El doctor Ramírez Echevarri agregó en su testimonio que él mismo había revisado las cuentas, en las cuales era evidente el desfalco ocasionado por los mayordomos, indios principales todos ellos, que llegaban a deber hasta más de cien pesos en el caso de la cofradía de San Andrés.

Al problema de las cuentas debía añadirse el que las tierras de dichas agrupaciones se encontraban dispersas, lo cual era un obstáculo para llevar un preciso control de ellas. El cura proponía reunir todas dentro de la archicofradía del Santísimo Sacramento, y depositarlas bajo el cuidado de una «gente de razón». Pero no lo había hecho saber a la comunidad, pues reconocía que a los indios no les faltaban motivos para entrar en discordia con la mencionada «gente de razón». ${ }^{37}$

El testimonio del doctor Ramírez debió tener un gran peso en la resolución del litigio. Don Miguel Primo de Ribera, Provisor Catedralicio, tomando en cuenta los argumentos presentados por el cura de Naucalpan, no dudó en confirmar a Montes de Oca como mayordomo de la cofradía y, en refuerzo de ello, afirmó que haría lo mismo en otros curatos y pueblos del arzobispado, porque en la mayor parte sucedía algo semejante. Incluso recordó que el Obispo Lorenzana estaba preocupado por los bienes de las cofradías de los pueblos, las cuales seguirían teniendo dificultades económicas mientras permanecieran bajo la administración de los indios. Pero también tendrían problemas si quisieran suprimir la mayor parte de las cofradías, para compendiar todas en la del Santísi-

${ }^{37}$ AGNM, Bienes Nacionales, vol. 230, exp. 5, f.5. 
mo Sacramento y en la de las Ánimas, pues provocaría inquietud y tumultos entre los indios.

El Provisor determinó que fueran los curas quienes indicaran a la persona que administrara dichos bienes, primero entre gente de razón, y luego a indios de más razón, de mejor conducta y hombres de bien que estuvieran lejos de cualquier sospecha ${ }^{38}$.

Pero la situación de las cofradías de Naucalpan no se resolvió con la sentencia del Provisor, pues en 1774 el doctor Ramírez Echevarri fue sustituido por el doctor Ramón Pérez. El nuevo cura encontró los informes de sus antecesores y retomó el asunto con mucho mayor interés. Escribió un detallado informe de la situación que guardaba el curato, denominado Statu Animarum, en el cual dirigía su atención a la falta de cuidado que los indios tenían en sus prácticas religiosas. La fábrica material de las iglesias ubicadas en los pueblos aledaños a Naucalpan, que dependían de ese curato, era desastroso. Algunas tenían tan sólo las paredes, y por la falta de techo, el interior se veía muy afectado en tiempo de lluvias. Por el evidente deterioro de las Iglesias era casi imposible celebrar la misa en esas condiciones.

Al igual que sus antecesores, el doctor Pérez focalizó su atención en la mala administración que los indios tenían de los bienes de las cofradías, con la siguiente descripción:

...cada mayordomo disfruta de los bienes de la Cofradía cometiendo con ello un expreso latrocinio = esto dimana de que los indios nombran mayordomo: éste que es Indios como ellos, roba cuánto le parece y como él vende los magueyes a los demás Indios, éstos están contentos con él, sino, al tiempo de las cuentas todo es discordias, querellas y chismes, que impiden al Cura el tiempo necesario para la administración y otras cosas de su obligación. ${ }^{39}$

En esta queja, el cura dirigía sus acusaciones al mayordomo y a los indios de los pueblos, quienes establecían, desde su punto de vista, una serie de complicidades que derivaban en robos del caudal de las cofradías.

En la descripción anterior iba implícito el concepto que se tenía de los indios en el siglo XVIII. Varios curas de ese tiempo se externaron opiniones nada favorables acerca de los indios, que podían ir desde su típica denominación de «miserables», en el sentido de desamparados, desafortunados y empobrecidos, hasta otros adjetivos peyorativos como ignorantes, maliciosos, mañosos, escandalosos, dados a la embriaguez, a la lujuria. También era frecuente hablar de

${ }^{38}$ Ibidem, f. 10v.

${ }^{39}$ APSBN, Serie Sacramental, Caja 53, Statu animarum, f. 2 v.

Hispania Sacra, LXIII

128, julio-diciembre 2011, 545-567, ISSN: 0018-215-X 
ellos con el calificativo de rudos, como sinónimo de rústicos, toscos o ásperos. ${ }^{40}$ Hipólito Villarroel ahonda en ese concepto de la siguiente manera:

El carácter del indio... es extremadamente malicioso, enemigo de la verdad, desconfiado, amigo de novedades, disturbios y alborotos; nada adictos a la religión católica y demasiado entregados a la superstición, a la idolatría y a otros vicios detestables... ${ }^{41}$

Este concepto de los indios con seguridad era compartido por los curas de Naucalpan, pues estaban seguros de que los naturales carecían de las capacidades necesarias para llevar adecuadamente las cuentas de las cofradías.

Pero el interés del doctor Ramírez iba más allá que dar un buen cuidado a las Iglesias y a los bienes de su curato. De acuerdo al informe dirigido al obispo Lorenzana, las cofradías no contaban con Constituciones, por lo que, además de redactarlas, sugería medidas drásticas para mejorar las cuentas parroquiales. Una de las cláusulas prohibía al Mayordomo vender o comprar cosa alguna con dinero de la cofradía, sin antes consultarlo con el cura, quien debía aprobar el gasto. Esto significaba la intervención directa del párroco en la administración de los bienes de los indios, que estaban depositados bajo el nombre de las cofradías. ${ }^{42}$

Por un lado sugería que las cofradías de los pueblos, las cuales contaban con tierras para su manutención, se redujeran a las más grandes, que estaban asentadas en la Iglesia parroquial. Incluso iba más allá, al sugerir que las capillas más deterioradas de los pueblos fueran completamente derruidas, con lo cual se obligaba a sus habitantes a asistir a la Iglesia Parroquial de San Bartolo. En su concepto, eso ayudaría al cuidado y bienestar religioso de su feligresía.

Además propuso que las iglesias de las haciendas cercanas, como la del Molino Prieto y la de Echegaray, estuvieran impedidas de celebrar la misa para gente que no fueran sus trabajadores..$^{43}$ Estas dos medidas tenían un solo objetivo: ampliar la base de feligreses, quienes debían de hacer sus limosnas y pagos parroquiales en San Bartolo Naucalpan. Dicho de otra manera, el interés del párroco por hacerse cargo de las cuentas de cofradías, y concentrar los servicios eclesiásticos en la parroquia tenía como objetivo elevar su salario.

\footnotetext{
${ }^{40}$ William Taylor, «...De corazón pequeño y ánimo apocado. Conceptos de los curas párrocos sobre los indios en la Nueva España del siglo XVIII» en W. TAYLOR, Entre el proceso global y el conocimiento local. Ensayos sobre el Estado, la sociedad y la cultura en el México del siglo XVIII, (Ed. Bajo el cuidado de Brian Connaughton), México, UAM-I, CONACYT, y Miguel Ángel Porrúa, 275 y 284.

${ }^{41} \mathrm{H}$. Villarroel, Enfermedades políticas que padece la capital de esta Nueva España, México, $1994,88$.

${ }^{42}$ APSBN, Serie Sacramental, vol. 53, Statu animorum, f. 11.

${ }^{43}$ Ibidem, f. 25.
} 
Es evidente que ambas medidas no eran bien recibidas por los indios, en especial el hecho de derrumbar sus capillas en los pueblos de visita, las cuales habían sido edificadas desde finales del siglo XVI y principios del siglo XVII. Por esa razón, no se habían llevado a cabo las consultas entre los indios que ordenó el obispo Lorenzana para aceptar las sugerencias del cura. Si previamente los indios habían iniciado un litigio por la intromisión de un español como mayordomo de la Cofradía del Santísimo, era evidente que su reacción ante estas medidas sería negativa. De hecho, es posible que el cura haya ido aplazando la consulta ante su feligresía, la cual finalmente se llevó a cabo con la presencia del gobernador de indios, alcaldes, regidores y pueblo en general. En su informe el cura aseguraba que los indios, después de escuchar las sugerencias acerca de los bienes de las cofradías y del destino de sus Iglesias, habían respondido favorablemente, pues oían el mandato, lo obedecían gustoso y daban por ello las debidas gracias a V.S. Ilustrísima, procediendo a la firma del documento. ${ }^{44}$

En realidad, y dado que quien hace la narración del los hechos era el propio cura párroco, no sabemos la reacción que tuvieron los indios al respecto. Pero puede suponerse una de dos situaciones, a saber: que la consulta no se llevó a cabo temiendo una reacción negativa de los indios, o que el comunicado no contenía los puntos escabrosos para los intereses de la república, como aquel en que se recomendaba que una persona «de razón» ocupara la mayordomía, tal y como ya se hacía en la Cofradía del Santísimo.

Lo que es un hecho es que las sugerencias del cura no se llevaron a cabo del todo, pues las Iglesias de los pequeños poblados siguieron en pie, gracias a lo cual son parte del patrimonio arquitectónico de esa zona. Por su parte, los bienes de las cofradías locales se conservaron, por lo menos hasta 1784, en que terminan varios de los libros de cuentas contenidos en el Archivo de la parroquia de San Bartolo Naucalpan.

Profundizar acerca de la situación de las cofradías de Naucalpan, permite catalogar a la acción de los curas no sólo como una intervención más sino incluso como una verdadera intromisión en la vida interior de los pueblos. Si bien, en teoría los bienes de cofradías eran parte de obras pías, es muy probable, como lo han mencionado algunos autores, que los indios hayan ido trasladando parte de los bienes de comunidad a estas hermandades. Dichos bienes estaban bajo la tutela del obispo, y no de las autoridades civiles, quienes tomaron cuenta de ellos para realizar los Reglamentos de los Pueblos, quitando a los indios la administración libre de sus bienes. ${ }^{45}$

44 Ibidem, f. 26 v.

45 William Taylor documenta varios casos en los que los indios defienden sus derechos ancestrales del manejo de sus bienes de cofradías, sobre los cuales demandaban su poder absoluto. W. TAYLOR, $M i$ nistros de lo sagrado... p. 462. D. TANCK, «Los bienes y la organización...»41-42.

Hispania Sacra, LXIII

128, julio-diciembre 2011, 545-567, ISSN: 0018-215-X 
Por otro lado, no obstante que la política de los Borbones de hacer a un lado a los curas de los bienes de la comunidad, tanto el Obispo Lorenzana, como muchos otros prelados, estuvieron en contra de considerar el cuidado de los bienes de las cofradías como un aspecto exclusivo de la comunidad. ${ }^{46}$

Por su parte, el enfrentamiento que curas e indios tuvieron por las cofradías rurales debe ser vista en el contexto del interés de los clérigos por seguir adelante en la carrera eclesiástica. El aumento de las entradas monetarias a raíz de la concentración de bienes y feligreses en la parroquia de Naucalpan, le permitiría al cura tener más dinero para invertir en la reconstrucción de las iglesias, así como en el ornato divino, lo cual se podría asentar en un curriculum exitoso, requisito indispensable para concursar por mejores curatos.

\section{LOS CURAS COMO RENTISTAS DE LOS INDIOS}

Los curas de parroquias rurales podían tener tratos económicos con los indios, más allá de las limosnas y emolumentos que obtenían por su labor evangélica. Cabe recordar que los pueblos solían tener tierras que ponían en renta, y que formaban parte de sus bienes de comunidad. Los indios otomíes de Tlalnepantla contaban con diversas tierras que ponían en arrendamiento, entre los cuales se encontraba el Rancho de San Nicolás. Esta propiedad estaba bajo el régimen de censo enfitéutico, de manera que quienes tenían el dominio útil, tenían la facultad de venderlo a la persona interesada, siempre y cuando fuera reconocido el pago anual de 2,000 pesos a los indios otomíes, quienes conservaban el dominio directo del rancho.

Uno de los muchos poseedores de la finca fue el doctor don Sebastián de Iturralde, segundo cura de Tlalnepantla. Los mismos indios ignoraban el año en que había comenzado a arrendar dicha hacienda. Pero el doctor Iturralde nunca pagó dicha renta, por lo que en 1790, año de su muerte, los indios exigieron el pago del adeudo, que era tan sólo uno más de los que dejó el Dr. Iturralde a su muerte.

La queja de los indios era muy grande, sobre todo porque dicho monto formaba parte de los sobrantes del arca de comunidad, que todavía en ese año podían aprovechar libremente. El hecho de ser párroco no lo eximía de pagar las obligaciones obtenidas por la renta del rancho de San Nicolás.$^{47}$ Por si esto fuera poco, los indios también lo acusaron de haber tomado 320 pesos de sobrantes de bienes de comunidad de varios pueblos del propio curato, y la causa de ello era que el arca se encontraba precisamente en las casas curales. Este señala-

\footnotetext{
46 William TAYLOR, «El camino de los curas...» op. cit. 99.

${ }^{47}$ AGNM, Ramo Indios, vol. 81, exp. 9, fs. 236-249.
} 
miento era todavía más grave que el anterior, pues si bien no se le menciona abiertamente, equivalía a un robo o a un abuso de confianza.

En 1801 el fiscal protector de los indios retomó el cobro del adeudo que Iturralde había dejado, pero con muy poco éxito, dado que el cura había dejado pendientes otras deudas, por lo que se había recurrido a concurso de acreedores. Tal parece que la deuda ante los indios de Tlalnepantla no había sido tomada en cuenta en dicho concurso, razón por la cual el abogado afirmaba que los caudales de los bienes de comunidad de los indios deben verse como cosa sagrada porque miran a la causa pública de los nacionales tan privilegiada que merecen en todo tiempo las primeras atenciones del soberano... ${ }^{48}$

Aunque no se existe documento que indique si los indios lograron la satisfacción de su demanda, lo que importa aquí es el abuso de confianza del cura respecto a los bienes de comunidad, en especial de los sobrantes, los cuales tendieron a mermarse cada día por la aplicación de las Reformas Borbónicas. Pero es un hecho que la posición del cura le favoreció para convertirse en rentista de los indios.

\section{LAS CANTERAS DE LA DISCORDIA. EL ENFRENTAMIENTO DE LOS INDIOS DE Totolinga CON LOS PREBENDAdOS DE LA ARQUIDIÓCESIS DE MÉXICO}

Los curas párrocos no fueron los únicos clérigos que tuvieron relaciones con los indios. El caso, que a continuación expongo, relata un enfrentamiento que sostuvieron los prebendados de la Arquidiócesis de México con los indios de San Lorenzo Totolinga, pueblo sujeto a San Bartolomé Naucalpan, y que se localiza en las cercanías del Santuario de los Remedios.

Como se recordará, dicho Santuario fue una capellanía a cargo de la ciudad de México, desde la segunda mitad del siglo XVI, por lo que los gastos y fábrica del templo corrieron por cuenta de la capital virreinal. El Ayuntamiento capitalino nombraba a los sacerdotes encargados de los sacramentos en Los Remedios, y se aprobaban las composturas necesarias para mantener el templo en buenas condiciones.

El Santuario quedó ubicado en el cerro conocido como Otoncalpulco, o lugar de los otomíes. A sus faldas se localizaban los pueblos de San Lorenzo Totolinga y San Juan Totoltepec, sujetos a San Bartolo Naucalpan.

Además del edificio religioso, la catedral metropolitana se reservó para sí unas minas de cantera que se encontraban en los cerros aledaños, cercanos al

${ }^{48}$ AGNM, Tierras, vol. 2852, exp. 6. 
pueblo de San Lorenzo Totolinga, de las cuales se extrajo una gran parte de la piedra que adornó tanto el sagrario metropolitano como otros importantes edificios de la ciudad. A fines del siglo XVII Agustín de Vetancourt hace una mención de la utilización de dicha piedra: de la más dura y bruta abundan los cerros en contorno, y en el sitio de los Remedios piedra de cantería para pilares....49

En 1712 los indios de Naucalpan, como muchos otros pueblos novohispanos, obtuvieron la composición de sus tierras, por un pago de cien pesos. Se les marcaron sus seiscientas varas a los quince pueblos sujetos a San Bartolo Naucalpan, entre los cuales estaba el de San Lorenzo Totolinga.$^{50}$ Este pueblo se había distinguido por dedicarse a explotar y labrar la cantera que se encontraban en su territorio. Sin embargo, la Iglesia Catedral estaba en posesión de una tierra colindante con la de los indios, en el rancho denominado Las Canteras.

Los representantes de la catedral también estuvieron de acuerdo con la medición de los bienes de comunidad de 1712. Pero desde 1741, los indios denunciaron ante la Real Audiencia el despojo de tales canteras que fueron realizando poco a poco los dueños de las demás minas cercanas, propiedad de otras haciendas de la localidad. Así comenzó un largo litigio en el que se vieron enfrentados los indios de Totolinga y los prebendados de la Catedral metropolitana. Uno de ellos inició otra demanda en 1745, por la cual acusaba a los indios de ser ellos quienes les habían impedido explotar dicha mina..$^{51}$

El asunto no se solucionó, y por el contrario, se agravó aún más, cuando en 1771 la mina de la Catedral tenía como arrendatario a José Antonio de Echegaray. Conocido personaje de la zona, por ser propietario de la hacienda de San Nicolás, a la que heredó su apellido, así como de otros pequeños ranchos en el actual municipio de Naucalpan, Echegaray se introdujo dentro de los límites de las tierras de los indios y aprovechó a sacar numerosas cargas de cantera, que vendió en la ciudad de México.

Para buscar una solución al conflicto, en ese mismo año de 1771, se llevó a cabo una nueva medición de las tierras y colindancias de los pueblos dependientes de San Bartolo Naucalpan, pero ésta no solucionó el conflicto con la Catedral. ${ }^{52}$ Dicho enfrentamiento tuvo muchos episodios en la última parte del siglo XVIII, algunas veces los indios iniciaban la demanda, y en otros casos fueron los representantes de la catedral quienes tomaban la iniciativa. Todavía

\footnotetext{
49 A. Vetacourt, Theatro Mexicano. Crónica de la provincia del Santo Evangelio de México... México, Impr. Por Doña María de Benavides, viuda de Juan de Rivera, 1698, Edición Facsimilar, México, 1971, 23.

${ }^{50}$ AGNM, Tierras, vol. 1208, exp. 4, f. 6-7.

${ }^{51}$ AGNM, Tierras, vol. 2504, exp. 13.

52 AGNM, Tierras, vol. 1579, exp. 1, fs. 24-32.
} 
en 1784 seguía la pugna entre ambas partes, sin un veredicto al respecto por parte de la Real Audiencia. ${ }^{53}$

Finalmente, de acuerdo a lo que se observa en las anotaciones del Reglamento de Indios de Tacuba, de 1806, en lo que se refiere a San Bartolo Naucalpan, se da a entender que ya se había llegado a una resolución: Se dice que ...en atención a que este pueblo se halla en el día en posesión de unas canteras de considerable producción, que existían en manos ajenas, prevengo al Subdelegado... que reparta a los indios necesitados que no tengan tierras de repartimiento las varas suficientes para su aplicación personal, y el resto de dichas canteras lo arriende en pública subasta...54 Es decir que, a pesar de que uno de los contendientes fue, ni más ni menos la propia Iglesia Catedral, la Real Audiencia terminó por amparar a los indios en la posesión.

Llama la atención de este caso que los indios se enfrentaron a los representantes catedralicios, entre ellos diversos prebendados, igual que lo hicieron contra otros vecinos que también querían despojarlos de la explotación de las canteras. Si bien este caso no se refiere a la participación de los curas párrocos, sí se puede ver que las propias autoridades catedralicias se vieron inmersas en litigios que no tenían nada que ver con asuntos espirituales, tal y como se pretendía en las Reformas Borbónicas.

En ese contexto, la Catedral no dudó en aprovechar todos los recursos que estuvieron a su mano, para defender sus bienes materiales, aún a costa de un pueblo de indios como el de San Lorenzo Totolinga. Si bien el Obispo Lorenzana recomendaba a los curas mantenerse al margen de negocios seculares, 55 por supuesto no fueron incluidos los clérigos de la propia sede diocesana.

\section{CONCLUSIONES}

Como se ha visto en los ejemplos expresados hasta aquí, los clérigos siguieron teniendo una presencia importante en la convivencia al interior de los pueblos de indios. En algunos casos sus opiniones fueron el fiel de la balanza en la resolución de diversos conflictos judiciales. Sin embargo, en algunos casos su intervención rayó en la intromisión directa, pues favorecieron a un grupo en detrimento de otro.

Su participación fue propiciada tanto por los indios como por las propias autoridades virreinales, quienes depositaban su confianza en el buen juicio de los

${ }^{53}$ AGNM, Indiferente virreinal, caja 68, exp. 3, fs. 1-2.

${ }^{54}$ AGNM, Indios, vol. 79, exp. 5, f. 100.

55 W. TAYLOR, Ministros de lo sagrado... 33 . 
curas. Asimismo, el papel que tuvieron los curas con respecto al adecuado manejo de los bienes de comunidad, a través de las tierras de los santos o las cofradías, fue prioritario, ya que se les reconoció como representantes de los propios indios. Esto llegó a ser incluso contraproducente para la misma comunidad, ya que a veces el cura tenía una opinión muy negativa del manejo que los indios hacían de dichos caudales, lo cual refuerza las afirmaciones desventajosas de otros párrocos de ese momento respecto de los indios.

Es un hecho que la relación entre curas e indios no siempre fue tersa, y que los intereses de unos y otros tropezaron con los asuntos económicos de ambos grupos. Cuando uno de ellos se veía amenazado, el enfrentamiento se realizó en los tribunales. Los clérigos no dudaron en defender sus ideas, aún en detrimento de su relación con los indios, lo cual es fruto de la política racional y ordenadora de los Borbones, en el marco de la secularización de los curatos de indios.

Por último, cabe resaltar que todos estos conflictos deben ser vistos siempre bajo la perspectiva de la carrera eclesiástica, que en el caso de los curatos rurales de Naucalpan y Tlalnepantla, fueron un eslabón en la cadena de ascenso por mejores cargos y curatos.

Este trabajo es tan sólo un acercamiento al comportamiento de los curas al interior de los pueblos, pues como se ha documentado, no se alejaron del todo de cuestiones materiales y de orden público, tal y como se pretendió que sucediera con la implementación de las Reformas Borbónicas. Valdría la pena replantear, con otros estudios semejantes y de mayor profundidad, el pretendido alejamiento de los curas en diversos asuntos materiales. 